\title{
Larvicidal effect of Endod (Phytolacca dodecandra) seed products against Anopheles arabiensis (Diptera: Culicidae) in Ethiopia
}

\author{
Ayalew Jejaw Zeleke ${ }^{1 *}$, Bezuayehu Alemayehu Shimo ${ }^{2}$ and Delenasaw Yewhalaw Gebre ${ }^{3}$
}

\begin{abstract}
Objective: The purpose of the present study was to determine the larvicidal effect of 'Endod' (Phytolacca dodecandra) seed products on Anopheles arabiensis, in Ethiopia.

Results: Experimental study was conducted using a total of 2400 third instars larvae of $A$. arabiensis. The seed products $P$. dodecandra showed larvicidal activity against 3rd-stage larvae of both the laboratory and field population of A. arabiensis. The $L_{99}$ values for $P$. dodecandra's seed powder and its extract form against the laboratory reared larvae were 121.07, and $616.46 \mathrm{mg} / \mathrm{l}$, respectively. The $\mathrm{LC}_{50}$ and $\mathrm{LC}_{95}$ values were also determined.
\end{abstract}

Keywords: Endod, Phytolacca dodecandra, Larvicidal, Lethal concentration

\section{Introduction}

Globally, an estimated 3.4 billion people were at risk of malaria with 627,000 malaria deaths in 2012. Out of the reported deaths, $90 \%$ occurred in SSA and the majority of these were children within the age of $<5$ years old $[1,2]$.

Malaria control strategies set out in Africa include on time treatment of clinical attack of malaria with an efficient anti-malarial drug along with proper usage of insecticides for vector control methods. However, its control achievement seems difficult due to the emergence of insecticide and antimalarial drug resistances [2, 3]. Furthermore, majority of the chemical insect killers are hurtful to man and animals [4].

In Ethiopia, population of Anopheles arabiensis, which is the major malaria transmitter vector, developed resistance to the conventional insecticides (dichlorodiphenyltrichloroethane, permethrin, deltamethrin and malathion) $[5,6]$. The emergence and widespread of insecticide resistance malaria vectors and the dreadful environmental impact of conventional insecticides

\footnotetext{
*Correspondence: ayalewjejaw@yahoo.com

${ }^{1}$ Department of Parasitology, School of Biomedical and Laboratory Sciences, College of Medicine and Health Sciences, University of Gondar, Gondar, Ethiopia

Full list of author information is available at the end of the article
}

emphasized the call for the development of alternative malaria control approaches [7].

Phytolacca dodecandra, which is commonly called as 'Endod' in Ethiopia, is one of among the most important plants in the country. It is also one of the most hopeful plant pesticides because of its high toxicity to the snails, and low toxicity to mammals [8]. However, as per of our knowledge, its toxicity was not investigated for its larvicidal effect against $A$. arabiensis, the major malaria vector in Ethiopia. Therefore, this study aimed to evaluate the larvicidal effect of its seed powder and crude extract form on this malaria vector.

\section{Main text \\ Methods \\ Study setting}

An experimental study was conducted in Jimma Univesrsity tropical and infectious diseases research centre from November to February 2016, Jimma, Ethiopia.

\section{Sample collection and seed product preparation}

Sample from 'Endod' (P. dodecandra) plant was collected in Mizan Aman town (220 km far away from Jimma). The plant species identification was confirmed and voucher of the specimen has been deposited at the National Herbarium in Addis Ababa University, Ethiopia. Then, berries 
were collected, washed and dried in the shade place. Finally, they were crushed and powdered using a mortar and pestle. The powder was stored in a dry shaded plastic container for several days prior to use in the laboratory trials [9-11]. Weights of the powder were measured using digital balance in milligram (mg). Accordingly, 0.5, $1,2,3,4$ and $5 \mathrm{mg}$ powder were prepared and each were added to $100 \mathrm{ml}$ distill water to form $5,10,20,30,40$, and $50 \mathrm{mg} / \mathrm{l}$ concentrations. In order to prepare test concentrations of the extract form, stock solution was obtained by adding $200 \mathrm{mg}$ of the powder into $20 \mathrm{ml}$ distill water. It was kept in a screw-cap vial for $24 \mathrm{~h}$ and shacked vigorously to dissolve the powder in the solvent and sieved using Whatman Paper. Then, the filtered liquid solutions were serially diluted and 6 test concentrations were obtained by adding $0.05,0.10,0.20,0.30,0.40$ and $0.50 \mathrm{ml}$ from stock solutions to containers of having $100 \mathrm{ml}$ distilled water as it is described previously [9].

\section{Larvae collection/rearing and bioassay}

The eggs of $A$. arabiensis mosquito were kept and developed to larvae under standard conditions $\left(25^{\circ} \mathrm{C} \pm 2{ }^{\circ} \mathrm{C}\right.$, $80 \% \pm 4 \%$ RH) [12]. Besides, weekly surveys were conducted from stagnant water, and ponds. Larval collection was done using the standard dipping method with a $350 \mathrm{ml}$ mosquito scoop. Morphological identification was done using the previously described mosquito identification key [13]. Then, 3rd-stage larvae were collected in plastic whirl-packs by trained workers from mosquito breeding sites and were transported to the laboratory. They were placed into plastic trays to be reared and feed crushed yeast and wheat flour. The trays had a capacity of holding 31 (liter) distilled water at $5 \mathrm{~cm}$ depth. Finally, 2400 larvae were reared in four trays (600 larvae per tray) by following standard methods [9].

After the larvae were being collected/reared, bioassay was performed. It was performed by using six treatment levels for each of the studied seed products. During the experiment, batches of 25 larvae were exposed to each test concentrations. Identical larval containers were used throughout the experiment and were filled by $100 \mathrm{ml}$ of distill water. The depth of the water in the container was $5 \mathrm{~cm}$. The larvae were transferred from the plastic trays to the container by using dropper and offered a small amount of crushed yeast and wheat flour. The powder and crude extract forms of the seed products were applied onto the water surface of the larval containers. Each test was monitored from the time of application to trial period $(24 \mathrm{~h})$ and the numbers of dead larvae were recorded. Dead parts were removed once they were discovered. In general, World health organization (WHO) susceptibility test procedure was followed as described before [9].

\section{Data quality control}

Each bioassay was repeated three times. The larval containers were thoroughly cleaned between each use and a fresh batch of larvae was used for each replicate. Critical care was taken while measuring the powder and preparing the concentration before the actual work was done. Whenever the mortality in the control was between 5-20\%, mortality was corrected using Abbott's formula and whenever it was $>20 \%$, the test was repeated [14]. Physicochemical parameters $(\mathrm{pH}$, temperature, turbidity, humidity) were measured at site with their corresponding measurement unit (multi-parameter measurements).

\section{Data processing and analysis}

The relationship between dose and mortality was analyzed using log dosage-probit mortality regression line with $95 \%$ confidence interval. Estimates of the LC values were calculated using probit analysis program version 1.5. Chi square test was used to determine the level of significance of the effects of treatments on larvae mortality. The alpha value was set at 0.05 with $\mathrm{p}<0.05$ was considered statistically significant.

\section{Results}

During the entire experiment of the study, a total of 2400 third instars larvae of $A$. arabiensis were used. This study revealed that unpurified seed products of $P$. dodecandra have a lethal effect on the larval stage of the vector. The powder and crude extract form of the seed products were applied on both the laboratory and field strains of the larvae.

\section{Larvicidal effect of Phytolacca dodecandra seed powder}

As it is presented on Table 1, there was a significant relation between the mortality rate of the larvae and the dose of the seed powder. Hundred percent (75 out of 75) of the laboratory strains of the larvae died at $50 \mathrm{mg} / \mathrm{l}$ dose of the powder and the $\mathrm{LC}_{99}$ values based on probit analysis was found to be $121.077 \mathrm{mg} / \mathrm{l}$. However, the LC values increased for the field population of $A$. arabiensis. For example, $50 \mathrm{mg} / \mathrm{l}$ of the powder brought $96 \%$ (72 out of 75 ) mortality rate and the $\mathrm{LC}_{99}$ value was elevated to $195.565 \mathrm{mg} / \mathrm{l}$.

\section{Larvicidal effect of Phytolacca dodecandra seed extract}

This study showed that the larval mortality rate increased with increasing plant extract concentration. The lowest and the highest mortality rate were observed at 5 and $50 \mathrm{mg} / \mathrm{l}$ of the crude seed extract form of $P$. dodecandra, respectively. Unlike the $50 \mathrm{mg} / \mathrm{l}$ of powder application, which results in $100 \%$ mortality rate on the laboratory populations of the vector, $50 \mathrm{mg} / \mathrm{l}$ of the extract form 
Table 1 Larvicidal effect of Phytolacca dodecandra seed powder against populations of Anopheles arabiensis, Ethiopia, 2016

\begin{tabular}{|c|c|c|c|c|c|c|c|c|}
\hline \multirow[t]{3}{*}{ Nature of the larvae } & \multicolumn{3}{|c|}{ Dose response } & \multicolumn{4}{|c|}{ LC values and confidence limits } & \multirow[t]{3}{*}{$p$ values } \\
\hline & \multirow[t]{2}{*}{ Conc. (mg/l) } & \multirow[t]{2}{*}{ No. tested } & \multirow[t]{2}{*}{ No. dead } & \multirow[t]{2}{*}{ LC } & \multirow[t]{2}{*}{ Mean conc. } & \multicolumn{2}{|l|}{$95 \% \mathrm{Cl}$} & \\
\hline & & & & & & Lower & Upper & \\
\hline \multirow[t]{8}{*}{ Laboratory strain } & 5.0 & 75 & 15 & 5 & 3.096 & 1.632 & 5.830 & 0.05 \\
\hline & 10.0 & 75 & 23 & 10 & 4.330 & 1.658 & 7.445 & \\
\hline & 20.0 & 75 & 42 & 15 & 5.430 & 1.735 & 8.815 & \\
\hline & 30.0 & 75 & 55 & 50 & 14.136 & 8.656 & 19.949 & \\
\hline & 40.0 & 75 & 66 & 85 & 36.802 & 25.383 & 76.791 & \\
\hline & 50.0 & 75 & 75 & 90 & 46.152 & 30.571 & 113.132 & \\
\hline & + cntrl & 75 & 75 & 95 & 64.544 & 39.622 & 204.145 & \\
\hline & - cntrl & 75 & 0 & 99 & 121.077 & 62.853 & 633.312 & \\
\hline \multirow[t]{8}{*}{ Field population } & 5.0 & 75 & 9 & 5 & 3.889 & 1.100 & 7.509 & 0.05 \\
\hline & 10.0 & 75 & 20 & 10 & 5.566 & 1.195 & 9.686 & \\
\hline & 20.0 & 75 & 30 & 15 & 7.089 & 1.935 & 11.566 & \\
\hline & 30.0 & 75 & 44 & 50 & 19.706 & 12.337 & 29.473 & \\
\hline & 40.0 & 75 & 55 & 85 & 54.783 & 35.068 & 168.437 & \\
\hline & 50.0 & 75 & 72 & 90 & 69.775 & 42.101 & 271.327 & \\
\hline & + cntrl & 75 & 75 & 95 & 99.851 & 54.553 & 556.383 & \\
\hline & -cntrl & 75 & 0 & 99 & 195.565 & 87.067 & 2179.398 & \\
\hline
\end{tabular}

conc. concentration, $+c n t r l$ positive control, $-c n t r l$ negative control

brought $80 \%$ (60 out of 75 ) of the larval death. The $\mathrm{LC}_{99}$ values against the laboratory and field populations were 616.461 and $846.394 \mathrm{mg} / \mathrm{l}$, respectively (Table 2).

The present study also conducted an experiment to assess the lethal effect of $P$. dodecandra seed products on non-target aquatic macro invertebrate organisms (Ceratopogonidae and Coenagrionidae). Dead macro invertebrates were identified by using microscope and family level identification key. The lethal dose of the plant products, which had resulted in 99\% of larvae mortality of $A$. arabiensis, had brought only up to $4 \%$ mortality rate on the non target organisms.

\section{Discussion}

The extensive usage of synthetic chemicals as mosquito control approach leads to the development of significant resistance to the majority of the chemicals that are available so far [3, 5-7]. Moreover, chemicals are not generally safe to the environment as they have hurtful effects on non target organisms [4]. However, there exists challenges for mosquito control using synthetic chemicals, there are opportunities for extra formulation of tools to manage the menace. Hence, it calls for researchers to invest their knowledge and search for alternative agents that are more efficient, cost-effective, and biodegradable natural insecticides from botanicals.
It is evident from the present study that, the exposures of $A$. arabiensis larvae to the seed products of $P$. dodecandra elicit larvae mortality. A substantial larvicidal effect of the seed products (both the powder and extract type) against third instars larvae of $A$. arabiensis was observed. In both forms of the seed product preparations, the larval mortality rate increased significantly with increasing in concentration. For example, $0.853 \mathrm{R}^{2}$ value from Logprobit analysis indicated that the $85.3 \%$ variation in larval mortality of laboratory strain of $A$. arabiensis might be explained due to the difference in concentration of the seed extract (Fig. 1).

As it is presented on both tables (Tables 1, 2), the required lethal doses for the field population of $A$. arabiensis was a bit higher than those for the laboratory cultivated larvae. In this context, the laboratory strain of $A$. arabiensis might be more delicate and liable to the seed products than the other group of the vector. This can be explained that field populations may develop adaptation to some hazard factors on the external environment. Nevertheless, it should be noted that the crude seed products of the studied plant have a toxic effect on both the laboratory and field populations of third stage larvae of the vector.

As far as the lethal potencies of the two preparation forms were concerned, the larvicidal potency of the 
Table 2 Larvicidal effect of Phytolacca dodecandra seed extract against populations of Anopheles arabiensis, Ethiopia, 2016

\begin{tabular}{|c|c|c|c|c|c|c|c|c|}
\hline \multirow[t]{3}{*}{ Nature of the larvae } & \multicolumn{3}{|c|}{ Dose response } & \multicolumn{4}{|c|}{ LC values and confidence limits } & \multirow[t]{3}{*}{$p$ values } \\
\hline & \multirow[t]{2}{*}{ Conc. (mg/l) } & \multirow[t]{2}{*}{ No. tested } & \multirow[t]{2}{*}{ No. dead } & \multirow[t]{2}{*}{ LC } & \multirow[t]{2}{*}{ Mean conc. } & \multicolumn{2}{|l|}{$95 \% \mathrm{Cl}$} & \\
\hline & & & & & & Lower & Upper & \\
\hline \multirow[t]{8}{*}{ Laboratory strain } & 5.0 & 75 & 9 & 5 & 3.694 & 1.179 & 8.089 & 0.05 \\
\hline & 10.0 & 75 & 15 & 10 & 5.900 & 1.590 & 11.096 & \\
\hline & 20.0 & 75 & 21 & 15 & 8.092 & 1.301 & 13.890 & \\
\hline & 30.0 & 75 & 31 & 50 & 30.764 & 19.634 & 67.537 & \\
\hline & 40.0 & 75 & 40 & 85 & 116.962 & 57.651 & 168.177 & \\
\hline & 50.0 & 75 & 60 & 90 & 160.422 & 71.143 & 377.243 & \\
\hline & + cntrl & 75 & 75 & 95 & 256.198 & 96.495 & 1255.738 & \\
\hline & - cntrl & 75 & 0 & 99 & 616.461 & 169.017 & $12,070.555$ & \\
\hline \multirow[t]{8}{*}{ Field population } & 5.0 & 75 & 5 & 5 & 4.899 & 2.790 & 6.981 & 0.05 \\
\hline & 10.0 & 75 & 11 & 10 & 7.849 & 5.149 & 10.315 & \\
\hline & 20.0 & 75 & 19 & 15 & 10.789 & 7.741 & 13.504 & \\
\hline & 30.0 & 75 & 27 & 50 & 41.390 & 34.399 & 53.176 & \\
\hline & 40.0 & 75 & 33 & 85 & 158.789 & 106.918 & 299.344 & \\
\hline & 50.0 & 75 & 49 & 90 & 218.258 & 138.593 & 454.521 & \\
\hline & + cntrl & 75 & 75 & 95 & 349.671 & 203.213 & 845.383 & \\
\hline & -cntrl & 75 & 0 & 99 & 846.394 & 415.301 & 2715.533 & \\
\hline
\end{tabular}

conc. concentration, + cntrl positive control, - cntrl negative control

powder form of the seed product was more powerful than its crude extract form (Fig. 2). This could be related with the application methods of the plant products. For instance, during the use of the crude extract, only drinking and inhalation of the extract might be happened. On the other hand, in the case of powder application, additional direct ingestion of the powder by the active feeding larvae stages of the vector might be

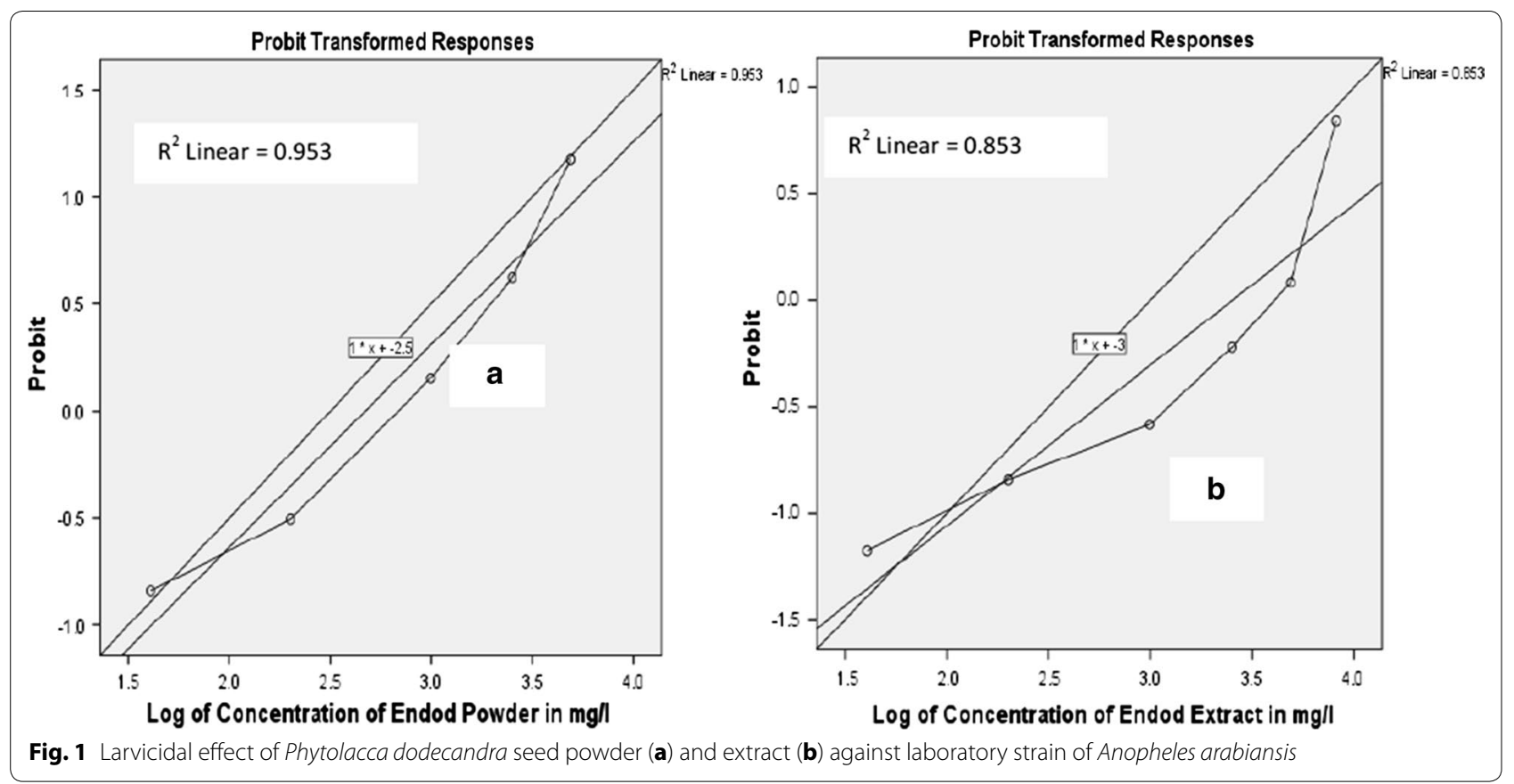




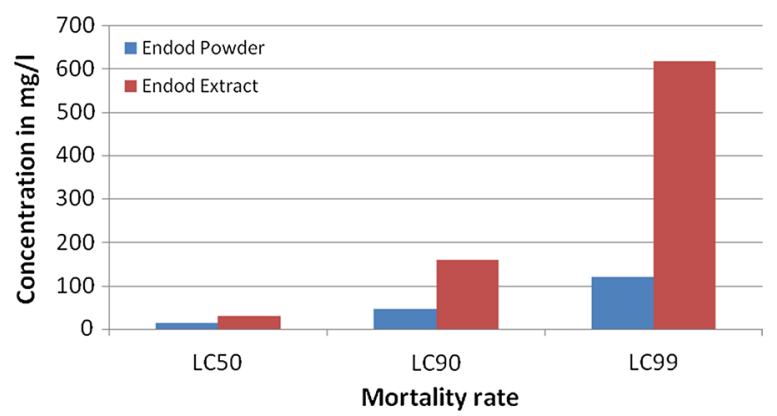

Fig. 2 Larvicidal effect of Phytolacca dodecandra seed products against laboratory strain of Anopheles arabiansis

occurred and this may in turn increased the dose of the biologically active ingredient within the larvae and this may made the powder form as it had more larvicidal potential than the other preparation. Moreover, the present study exclusively used purified water, which is poor extracting solvent. However, this finding revealed that 'Endod' seed products had an excellent larvicidal potency against $A$. arabiensis. Similarly, Getachew D et al. highlighted that, fresh and aged endod berry's solutions had a significant lethal effect against the 4thstage larvae of $A$. arabiensis [15]. It is also supported by other previous study that the crude seed products of $P$. dodecandra showed an admirable larvicidal and pupicidal properties against immature C. quinquefasciatus [16].

Interestingly, this study also pointed out that the studied plant didn't have significant lethal effect on non target organisms and this indicated that the plant products may have minimal effects on the non target organisms and works environmental friendly. Similarly, a few scholars had clearly put evidences that; products of $P$. dodecandra had toxic effects on different medically important vectors and parasites and low toxicity to mammals $[17,18]$.

\section{Conclusion}

The crude preparations of $P$. dodecandra seed products are a promising weapon to control malaria endemic. It can be suitable for temporary mosquito control in small man made breeding places.

\section{Limitations}

The major limitation of the present study is that:

- Its effect was not evaluated on all developmental stages of the vector.

- Besides, due to recourses related constraints, the present study was not able to identify and characterize the bioactive ingredients of its products.

\section{Abbreviations}

LC: lethal concentration; ml: milliliter; mg/l: milligram/liter; SSA: sub-Saharan Africa; WHO: World Health Organization.

\section{Authors' contributions}

AJZ conceived the study, perform the experiment, involved in data analysis and wrote the first draft of the manuscript. BAS conducted the literature review and analysis. DYG supervised the overall work. All authors read and approved the final manuscript.

\section{Author details \\ 1 Department of Parasitology, School of Biomedical and Laboratory Sciences, College of Medicine and Health Sciences, University of Gondar, Gondar, Ethio- pia. ${ }^{2}$ Department of Public Health, College of Health Sciences, Mizan Tepi University, Mizan Teferi, Ethiopia. ${ }^{3}$ Department of Biology, College of Natural Sciences, Jimma University, Jimma, Ethiopia.}

\section{Acknowledgements}

We wish to acknowledge Mizan Tepi University for the financial support of the study. We are also grateful to the National Herbarium in Addis Ababa University, who co-operated the identification of the plant specimen.

\section{Competing interests}

The authors declare that they have no competing interests.

\section{Availability of data and materials}

All data generated or analyzed during this study are included in this published article.

\section{Consent for publication}

Not applicable.

Ethics approval and consent to participate

Not applicable.

\section{Funding}

The research was funded by Mizan Tepi University.

\section{Publisher's Note}

Springer Nature remains neutral with regard to jurisdictional claims in published maps and institutional affiliations.

Received: 1 November 2016 Accepted: 31 August 2017

Published online: 06 September 2017

\section{References}

1. Caraballo H. emergency department management of mosquitoborne illness: malaria, dengue, and West Nile virus. Emerg Med Pract. 2014;16(5):1-23.

2. WHO. World malaria report. Geneva: World Health Organization; 2013.

3. Maharaj R, Morris N, Seocharan I, Kruger P, Moonasar D, Mabuza A, Raswiswi E, Raman J. The feasibility of malaria elimination in South Africa. Malar J. 2012:11:423.

4. Ghosh A, Chowdhury N, Chandra G. Plant extracts as potential mosquito larvicides. Indian J Med Res. 2012;135:581-98.

5. Yewhalaw D, Kassahun W, Woldemichael K, Tushune K, Sudaker M, Kaba D, Duchateau L, Van Bortel W, Speybroeck N. The influence of the GilgelGibe hydroelectric dam in Ethiopia on caregivers' knowledge, perceptions and health-seeking behaviour towards childhood malaria. Malar J. 2010;9:47.

6. Yewhalaw D, Wassie F, Steurbaut W, Spanoghe P, Van Bortel W, Denis L, Tessema DA, Getachew Y, Coosemans M, Duchateau L, Speybroeck N. Multiple insecticide resistance: an impediment to insecticide-based malaria vector control program. PLoS ONE. 2011:6:e16066.

7. Shaalan EA-S, Canyon D, Younes MWF, Abdel-Wahab H, Mansour A-H. Areview of botanical phytochemicals with mosquitocidal potential. Environ Int. 2005;31:1149-66. 
8. Peter $\mathrm{H}$, Mansfeld's encyclopedia of agricultural and horticultural crops (except ornamentals), Berlin: Springer; 2001.

9. World Health Organization. Guidelines for testing. Geneva;2005

10. Trudel and Bomblies. Larvicidal effect of chinaberry (Meliaa azederach) powder on Anopleles arabiensis in Ethiopia. Parasit Vectors. 2011;4:72.

11. Shiberu T, Ashagre H, Negeri M. Laboratory evaluation of different botanicals for the control of termite, Microterms spp. (Isoptera: Termitidae). Open Access Sci Rep. 2013;2013(2):1-3.

12. Das ND, Goswami D, Rabha B. Preliminary evaluation of mosquito larvicidal efficacy of plant extracts. J Vector Borne Dis. 2007:44:145

13. Gimba UN, Idris HS. Morphological identification and distribution of anopheles species in Gwagwalada town, FCT, Nigeria. Int J Environ Sci Toxicol Res. 2014;2(10):210-6.

14. Abbott WS. A method of computing the effectiveness of an insecticide. J Econ Entomol. 1925;18:265-7.

15. Getachew D, Balkew M, Gebre-Michael T. Evaluation of Endod (Phytolacca dodecandra: Phytolaccaceae) as a larvicide against Anopheles arabiensis, the principal vector of malaria in ethiopia. J Am Mosq Control Assoc. 2016;32(2):124-9.
16. Misganaw Nurie, Moges Shiferaw, Tadele Muche, Tesera Mamaye, Temesgen Tigab, Raja Nagappan. Evaluation of multi potential bioactive Endod, Phytolacca dodecandra (L'Herit) berries extracts against immature filarial vector Culex quinquefasciatus (Diptera: Culicidae). Res J Environ Earth Sci. 2012;4(7):697-703.

17. Lemma A, Brody G, Newell GW, Parkhurst RM, Skinner WA. Endod (Phytolacca dodecandra), a natural product molluscicide: Increased potency with butanol extraction. J Parasitol. 1972;58:104-7.

18. Madhina D, Shiff C. Prevention of snail miracidia interactions using Phytolacca dodecandra (L'Herit) (endod) as a miracidiacide: an alternative approach to the focal control of schistosomiasis. Trop Med Int Health. 1996;1 (2):221-6.

\section{Submit your next manuscript to BioMed Central and we will help you at every step:}

- We accept pre-submission inquiries

- Our selector tool helps you to find the most relevant journal

- We provide round the clock customer support

- Convenient online submission

- Thorough peer review

- Inclusion in PubMed and all major indexing services

- Maximum visibility for your research

Submit your manuscript at www.biomedcentral.com/submit 